\title{
Effects of dietary supplementation with Pediococcus acidilactici ZPA017 on reproductive performance, fecal microbial flora and serum indices in sows during late gestation and lactation
}

\author{
Hui Liu', Sixin Wang ${ }^{1}$, Dongyan Zhang ${ }^{1}$, Jing Wang ${ }^{1}$, Wei Zhang ${ }^{1}$, Yamin Wang ${ }^{1}$, and Haifeng Ji ${ }^{1, *}$
}

\begin{abstract}
* Corresponding Author: Haifeng Ji Tel: +86-10-51-503-865, Fax: +86-10-51-503-498, E-mail: jhf207@126.com
\end{abstract}

'Institute of Animal Husbandry and Veterinary Medicine, Beijing Academy of Agriculture and Forestry Sciences, Beijing 100097, China

ORCID

Hui Liu

https://orcid.org/0000-0003-0135-6845

Sixin Wang

https://orcid.org/0000-0001-8481-6151

Dongyan Zhang

https://orcid.org/0000-0002-8662-082X

Jing Wang

https://orcid.org/0000-0002-6513-8663

Wei Zhang

https://orcid.org/0000-0001-8815-2452

Yamin Wang

https://orcid.org/0000-0003-1932-8121

Haifeng Ji

https://orcid.org/0000-0001-5436-1782

Submitted Oct 10, 2018; Revised Feb 13, 2019; Accepted Apr 20, 2019
Objective: This study was conducted to determine the effects of dietary supplementation with Pediococcus acidilactici (P. acidilactici) ZPA017 as a probiotic on reproductive performance, fecal microbial flora and serum indices in sows during late gestation and lactation. Methods: A total of 94 sows (Large WhitexYorkshire, average 4.50 parities) were randomly allotted to two dietary treatments: control diet and the diet supplemented with P. acidilactici ZPA017 ( $2.40 \times 10^{9}$ colony-forming unit $/ \mathrm{kg}$ of diets). The study started at $\mathrm{d} 90$ of gestation and conducted until $\mathrm{d} 28$ of lactation.

Results: Compared to sows fed the control diet, supplementation of P. acidilactici ZPA017 increased the number of weaning piglets, weaning weight of litter and piglets, survival rate of piglets at weaning $(\mathrm{p}<0.05)$, and decreased diarrhea rate of piglets in lactation $(\mathrm{p}<0.05)$. Dietary P. acidilactici ZPA017 increased fecal Lactobacillus populations $(\mathrm{p}=0.030)$ and reduced fecal Escherichia coli and Staphylococcus aureus populations $(\mathrm{p}<0.05)$ of sows at weaning. Moreover, the supplementation of $P$. acidilactici ZPA017 increased serum concentrations of immunoglobulin $\mathrm{G}$, immunoglobulin $\mathrm{A}$ and total protein $(\mathrm{p}<0.05)$, while decreased serum haptoglobin concentration and alanine aminotransferase activity $(\mathrm{p}<0.05)$ of sows at weaning. Conclusion: Administration of P. acidilactici ZPA017 in diets during late gestation and lactation had positive effects on the reproductive performance, intestinal microflora balance and immunity of sows.

Keywords: Fecal Microbial Flora; Pediococcus acidilactici; Reproductive Performance; Serum Indices; Sows

\section{INTRODUCTION}

Although antibiotics have been used in diets for pregnant sows to improve the viability of their progeny in the past several decades [1-3], antibiotics-resistant microbes are a growing issue that has been exacerbated by the overuse and misuse of antibiotics. Therefore, it is urgent to find alternatives for antibiotics especially after the ban on the use of antibiotics as a growth promoter in Europe since 2006. Probiotics have received increasing interest as an alternative to maintain animal health and performance.

Probiotics are defined as live microorganisms that, when administered in adequate amounts, confer a health benefit on the host [4]. Several studies have evaluated the effects of probiotics on the reproductive performance of sows. Böhmer et al [5] reported that dietary Enterococcus faecium DSM 7134 in sows from d 90 of pregnancy to d 28 of lactation showed an improvement of lactation feed intake, litter size and weight performance of sows. Alexopoulos et al [6] investigated the effects of a dietary probiotic (containing Bacillus licheniformis and Bacillus subtilis spores) in sows and reported that the probiotic improved the reproductive 
performance of sows, with reduced piglet diarrhea, reduced pre-weaning mortality, and increased weaning weights. However, to date, little research has been performed to determine the effects of Pediococcus acidilactici (P. acidilactici) on sows.

Pediococcus acidilactici is a gram-positive, coccus-shaped, lactic acid- fermenting bacterium that belongs to the Lactobacillaceae family. P. acidilactici has been used as a probiotic for pigs, poultry, aquaculture and human dietary supplements $[7,8]$. P. acidilactici ZPA017 was isolated from the feces of a healthy pig in our laboratory. The strain was identified through standard morphological, biochemical and physiological tests by 16s rRNA gene sequence analysis at the China General Microbiological Culture Collection Center (Beijing, China). Therefore, the aim of this study was to investigate the effects of $P$. acidilactici ZPA017 on the reproductive performance, fecal microbial flora and serum indices in sows during late gestation and lactation.

\section{MATERIALS AND METHODS}

\section{Ethics statement}

The study was carried out in accordance with the recommendations of guidelines set by the Animal Care and Use Committee (permit number: SYXK-2017-0005) of the Institute of Animal Husbandry and Veterinary Medicine, Beijing Academy of Agriculture and Forestry Sciences (IAHVM-BAAFS), Beijing, China. The protocols were approved by the Animal Care and Use Committee of IAHVM-BAAFS.

\section{Animals, diets, and housing}

A total of 94 sows (Large WhitexYorkshire, average 4.50 parities) were randomly allotted to 2 dietary treatments including control diet with no probiotic and probiotic diet supplemented with $P$. acidilactici ZPA017 (2.40 $\times 10^{9}$ colony-forming unit $/ \mathrm{kg}$ of diets) based on parity and body weight. All diets were formulated to meet or exceed all nutrient requirement of NRC [9]. The ingredient and chemical composition of the basal diet for gestating and lactating sows are shown in Table 1. In this study, P. acidilactici ZPA017 freeze-dried powder was incorporated in the probiotic diet via corn substitution. The trial started at d 90 of gestation and conducted until d 28 of lactation. From d 90 to $\mathrm{d} 107$ of gestation, all sows were housed in individual gestation stalls $\left(2.2 \times 0.7 \mathrm{~m}^{2}\right)$ and fed gestation diets. Then, sows were moved to farrowing crates $(2.5 \times 1.8$ $\mathrm{m}^{2}$ ) and were fed lactation diets from $\mathrm{d} 108$ of gestation until weaning. The farrowing room temperature was maintained at $18^{\circ} \mathrm{C}$ to $25^{\circ} \mathrm{C}$ with $60 \%$ relative humidity. From d 90 of gestation until the day of farrowing, the sows were fed $3.0 \mathrm{~kg} / \mathrm{d}$ of diet. On the day of farrowing, sows were fasted. The sows were fed $2.0 \mathrm{~kg}$ diet on $\mathrm{d} 1 \mathrm{of}$ lactation. Thereafter, the amount of feed allowance increased gradually ( $1.0 \mathrm{~kg}$ each day) for the first week. Sows were then fed ad libitum until weaning
Table 1. Ingredients and chemical composition of the control diets (as-fed basis)

\begin{tabular}{|c|c|c|}
\hline Items & Gestation & Lactation \\
\hline \multicolumn{3}{|l|}{ Ingredient composition (g/kg) } \\
\hline Corn & 664.3 & 650.5 \\
\hline Wheat bran & 120 & 50 \\
\hline Soybean meal & 170 & 220 \\
\hline Fish meal & - & 20 \\
\hline Soy oil & 10 & 20 \\
\hline Limestone & 11 & 12 \\
\hline Dicalcium phosphate & 10 & 12 \\
\hline Salt & 4 & 4 \\
\hline L-lysine. $\mathrm{HCl}(98 \%)$ & 0.7 & 1.5 \\
\hline $\begin{array}{l}\text { Vitamin and mineral premix } \\
\text { for pregnant sows }\end{array}$ & 10 & - \\
\hline $\begin{array}{l}\text { Vitamin and mineral premix } \\
\text { for nursing sows }\end{array}$ & - & 10 \\
\hline \multicolumn{3}{|l|}{ Chemical composition (\%) } \\
\hline Digestible energy $(\mathrm{MJ} / \mathrm{kg})^{3)}$ & 13.30 & 13.80 \\
\hline (rude protein ${ }^{4)}$ & 14.50 & 18.05 \\
\hline (alcium ${ }^{4)}$ & 0.78 & 0.92 \\
\hline Total phosphorus $s^{4)}$ & 0.54 & 0.62 \\
\hline Lysine $e^{3)}$ & 0.72 & 1.05 \\
\hline Methionine+cysteine ${ }^{3)}$ & 0.38 & 0.57 \\
\hline
\end{tabular}

1) Provided the following quantities per kilogram of complete diet: vitamin $A_{4}$ 10,000 IU; vitamin $D_{3}, 2,000$ IU; vitamin $E, 30$ mg; vitamin $K_{3}, 1.5$ mg; vitamin $B_{1}$, $2.5 \mathrm{mg}$; vitamin $B_{2}, 5.5 \mathrm{mg}$; vitamin $B_{6}, 2.5 \mathrm{mg}$; vitamin $B_{12}, 0.02 \mathrm{mg}$; biotin, 0.2 $\mathrm{mg}$; niacin, $25 \mathrm{mg}$; pantothenic acid, $13 \mathrm{mg}$; choline chloride, $200 \mathrm{mg} ; 10 \mathrm{mg}$ of $\mathrm{Cu}$ as $\mathrm{CuSO}_{4} \cdot 5 \mathrm{H}_{2} \mathrm{O} ; 80 \mathrm{mg}$ of Fe as FeSO ${ }_{4} \cdot \mathrm{H}_{2} \mathrm{O} ; 25 \mathrm{mg}$ of $\mathrm{Mn}$ as $\mathrm{MnSO}_{4} \cdot \mathrm{H}_{2} \mathrm{O} ; 100$ $\mathrm{mg}$ of $\mathrm{Zn}$ as $\mathrm{ZnSO}_{4} \cdot \mathrm{H}_{2} \mathrm{O} ; 0.15 \mathrm{mg}$ of I as $\mathrm{K} ; 0.3 \mathrm{mg}$ of $\mathrm{Se}$ as $\mathrm{Na}_{2} \mathrm{SeO}_{3}$.

2) Provided the following quantities per kilogram of complete diet: vitamin $A, 7,000$ $\mathrm{IU}$; vitamin $\mathrm{D}_{31}, 1,500 \mathrm{IU}$; vitamin $\mathrm{E}_{1} 80 \mathrm{mg}$; vitamin $\mathrm{K}_{31}, 1.5 \mathrm{mg}$; vitamin $\mathrm{B}_{1} 1.8$ $\mathrm{mg}$; vitamin $\mathrm{B}_{2}, 5.5 \mathrm{mg}$; vitamin $\mathrm{B}_{6}, 4 \mathrm{mg}$; vitamin $\mathrm{B}_{12}, 0.03 \mathrm{mg}$; biotin, $0.2 \mathrm{mg}$; niacin, $25 \mathrm{mg}$; pantothenic acid, $13 \mathrm{mg}$; choline chloride, $200 \mathrm{mg} ; 20 \mathrm{mg}$ of $\mathrm{Cu}$ as $\mathrm{CuSO}_{4} \cdot 5 \mathrm{H}_{2} \mathrm{O} ; 100 \mathrm{mg}$ of Fe as FeSO $\mathrm{F}_{4} \cdot \mathrm{H}_{2} \mathrm{O} ; 25 \mathrm{mg}$ of $\mathrm{Mn}$ as $\mathrm{MnSO}_{4} \cdot \mathrm{H}_{2} \mathrm{O} ; 100 \mathrm{mg}$ of $\mathrm{Zn}$ as $\mathrm{ZnSO}_{4} \cdot \mathrm{H}_{2} \mathrm{O} ; 0.5 \mathrm{mg}$ of I as $\mathrm{Kl} ; 0.3 \mathrm{mg}$ of $\mathrm{Se}$ as $\mathrm{Na}_{2} \mathrm{SeO}_{3}$.

3) Calculated value.

${ }^{4)}$ Analyzed value.

at $\mathrm{d} 28$ of lactation. The diets were supplied twice a day (07:00 and 15:00) and sows had ad libitum access to water throughout the experimental period.

\section{Performance measurement}

Individual sows were weighed at $\mathrm{d} 108$ of gestation and $\mathrm{d} 28$ of lactation to determine weight loss. The feed intake during lactation was recorded for each sow to calculate average daily feed intake. Within $12 \mathrm{~h}$ after birth, the number of piglets born, born alive and dead were recorded. Piglets were individually weighed at birth and weaning (d 28 of lactation) to calculate average daily gain. At weaning, the number of weaned piglets was recorded. The diarrhea incidence in piglets within litters was evaluated according to a previous study [10] as follows: Diarrhea incidence (\%) $=$ (Total number of pigs with diarrhea)/(total number of pigs $\times$ experimental days) $\times 100$. Fresh excreta were graded using the following scale: $0=$ solid, $1=$ semisolid, $2=$ semiliquid, and $3=$ liquid. The 
occurrence of diarrhea was defined as production of grade 2 or 3 feces for 2 continuous days.

\section{Fecal samples collection and microbiological determination}

To determine the microbiological status of sows, fresh fecal samples were collected from the sows (10 randomly selected sows per treatment with the similarly parity) on $\mathrm{d} 28$ of lactation. The microbiological assay of fresh fecal samples was carried out as previously described by Choi et al [11]. Fecal samples were subjected to a series of 10 -fold dilutions in sterile physiological saline and incubated in duplicate on selective medium. The colony counts were then enumerated after culturing in Petri plates with the corresponding culture media: MacConkey agar for Escherichia coli (E. coli), Baird-Parker agar for Staphylococcus aureus (S. aureus), and de Mann, Rogosa and Sharpe (MRS) agar for Lactobacillus. The plates were incubated at $37^{\circ} \mathrm{C}$ for $48 \mathrm{~h}$. Bacterial counts were log transformed before statistical analysis.

\section{Blood collection and analysis}

Blood samples $(5 \mathrm{~mL})$ were obtained using vacuum blood collection tubes from an ear vein of 10 randomly selected sows per treatment with a similarly parity on the final day of the trial. After centrifugation $\left(3,000 \times g\right.$ for $15 \mathrm{~min}$ at $\left.4^{\circ} \mathrm{C}\right)$, serum was collected and stored at $-20^{\circ} \mathrm{C}$ until analysis. Enzyme-linked immunosorbent assays were used to determine the concentrations of immunoglobulins (IgG, IgM, and IgA;
Bethyl Laboratories, Inc., Montgomery, TX, USA) and haptoglobin (alpha diagnostic international, San Antonio, TX, USA). Serum concentrations of albumin, globulin, total protein, glucose, blood urea nitrogen and the serum activities of alanine aminotransferase and aspartate aminotransferase were determined using automatic biochemical analyzer (Model 7020; Hitachi, Tokyo, Japan) with corresponding kits (Nanjing Jiancheng Bioengineering Institute, Nanjing, China).

\section{Statistical analysis}

All experimental data were analyzed using the general linear model procedure of SAS version 9.2 (SAS Institute, Inc., Cary, NC, USA) as a randomized complete block design according to their body weight. The individual sow or litter of piglets was used as experimental unit. The analysis of piglets weaning weight used birth weight as covariates. Lactation length was used as a covariate for piglets survivability, sows and piglets weaning weight, sow feed intake and piglets average daily gain. Duncan's multiple range test, and a probability level of $\mathrm{p}<0.05$ was regarded as statistically significant.

\section{RESULTS}

Dietary P. acidilactici ZPA017 increased the number of piglets at weaning, survival rate at weaning, weight of piglets at weaning and litter weight at weaning $(\mathrm{p}<0.05)$, and decreased diarrhea incidence of piglets $(\mathrm{p}<0.05)$ compared with sows fed control diet (Table 2).

Table 2. Effects of dietary Pediococcus acidilactici ZPA017 supplementation on reproductive performance of sows during late gestation and lactation

\begin{tabular}{|c|c|c|c|c|}
\hline Items & Control $^{1)}$ & Probiotic $^{1)}$ & SEM & $p$-value \\
\hline \multicolumn{5}{|l|}{ Sows } \\
\hline Number of sows & 47 & 47 & & \\
\hline Average parity & 4.89 & 4.51 & 0.181 & 0.954 \\
\hline Sow body weight on day 108 of gestation $(\mathrm{kg})$ & 281.3 & 278.9 & 3.769 & 0.541 \\
\hline Sow body weight at weaning $(\mathrm{kg})$ & 248.2 & 241.4 & 3.333 & 0.237 \\
\hline Body weight change (kg) & 33.1 & 37.5 & 1.077 & 0.575 \\
\hline Lactation average daily feed intake of sows $(\mathrm{kg} / \mathrm{d})$ & 4.90 & 5.00 & 0.222 & 0.304 \\
\hline Total born/litter & 11.57 & 11.63 & 0.362 & 0.930 \\
\hline Born alive/litter & 11.04 & 11.26 & 0.335 & 0.761 \\
\hline Live-born rate (\%) & 96.52 & 96.81 & 0.848 & 0.441 \\
\hline \multicolumn{5}{|l|}{ Piglets } \\
\hline Litter weight of live-born piglets at birth $(\mathrm{kg})$ & 15.43 & 16.51 & 0.532 & 0.323 \\
\hline Weight of live-born piglets at birth (kg) & 1.42 & 1.48 & 0.044 & 0.433 \\
\hline Litter weight at weaning (kg) & 60.45 & 69.33 & 2.441 & 0.037 \\
\hline Weight of piglets at weaning $(\mathrm{kg})$ & 6.19 & 6.65 & 0.115 & 0.049 \\
\hline Number of piglets at weaning & 9.65 & 10.37 & 0.293 & 0.031 \\
\hline Survival rate at weaning (\%) & 88.68 & 92.42 & 1.480 & 0.023 \\
\hline Average daily gain (g/d) & 170.33 & 184.91 & 4.532 & 0.110 \\
\hline Diarrhea rate of piglets $(\%)^{2)}$ & 8.30 & 3.38 & 0.064 & 0.023 \\
\hline
\end{tabular}

SEM, standard error of means; CFU, colony-forming unit.

1) Control, control diet; Probiotic, control diet supplemented with Pediococcus acidilactici ZPA017 (2.40 $\times 10^{9} \mathrm{CFU} / \mathrm{kg}$ of diets).

2) Diarrhea incidence $(\%)=($ Total number of pigs with diarrhea) $/($ total number of pigs $\times$ experimental days $) \times 100$. 
Dietary P. acidilactici ZPA017 increased fecal Lactobacillus populations $(\mathrm{p}=0.030)$ and reduced fecal E.coli and S. aureus populations $(\mathrm{p}<0.05)$ compared with sows fed control diet (Table 3).

Compared with sows fed control diet, supplementation of P. acidilactici ZPA017 in diets increased serum IgG, IgA, and total protein concentrations $(\mathrm{p}<0.05)$, while decreased serum haptoglobin concentration and alanine aminotransferase activity $(\mathrm{p}<0.05)$ of sows at weaning (Table 4$)$.

\section{DISCUSSION}

Dietary supplementation of probiotics can increase the production and activities of digestive enzymes in the gut, improve gut health and nutrient digestibility, and therefore benefit nutrient utilization and growth performance of pigs [12-14]. Previous studies have shown that supplementation of probiotics in diets could improve the reproductive performance and health status of sow and litter [15-17]. In the present study, dietary supplementation with $P$. acidilactici ZPA017 increased weight of piglets at weaning and litter weight at weaning. This result is similar to the findings of Kim et al [18], who reported that higher litter weight was observed when sows were fed yeast culture during gestation and lactation. The present study also indicated that in comparison to sows fed diets without probiotics, the number of piglets at weaning and survival rate increased. Similarly, to our results, Taras et al [19] reported that the rate of survival piglets at weaning were improved in sows fed Enterococcus faecium NCIMB 10415. Additionally, in the present study, P. acidilactici ZPA017 supplementation to sows during late gestation and lactation reduced the incidence of diarrhea in their piglets, which was consistent with the result of Alexopoulos et al [6] who reported a lower diarrhea score in piglets from sows administered with Bacillus licheniformis and Bacillus subtilis. These results in current study suggested that the administration of $P$. acidilactici ZPA017
Table 3. Effects of dietary Pediococcus acidilactici ZPA017 supplementation on fecal microbial populations of sows at weaning $\left(\log _{10}\right.$ CFU/g)

\begin{tabular}{lcccc}
\hline Items & Control $^{1)}$ & Probiotic $^{1)}$ & SEM & p-value \\
\hline Escherichia coli & 7.63 & 6.43 & 0.324 & 0.038 \\
Staphylococcus aureus & 6.26 & 5.98 & 0.272 & 0.047 \\
Lactobacillus & 8.51 & 9.11 & 0.151 & 0.030
\end{tabular}

SEM, standard error of means; CFU, colony-forming unit.

1) Control, control diet; Probiotic, control diet supplemented with Pediococcus acidilactici ZPA017 $\left(2.40 \times 10^{9}\right.$ CFU/kg of diets).

could improve the health and reproductive performance of sows. One possible explanation could be that the improved microbial balance in the gut is optimized and a better utilization of nutrients is taking place, improving the health status of sows.

Lactic acid bacteria could produce short chin fatty acids and lactic acid, which may help to improve the intestinal microbial balance by reducing the $\mathrm{pH}$ of the intestinal content and inhibiting the growth and multiplications of opportunistic enteropathogens such as Salmonella spp. or strains of E. coli [20-22]. In the current study, P. acidilactici ZPA017 supplementation to diets for sows reduced the fecal E. coli and $S$. aureus concentration and increased the fecal Lactobacillus concentration. This indicated that the strain $P$. acidilactici ZPA017 could regulate the balance of intestinal microflora and establish a healthier gut, which had beneficial effects in improving the health and reproductive performance of sows, as supported by the results in this study. However, Scharek et al [23] demonstrated no differences in fecal bacterial populations of sows administered with Enterococcus faecium SF68 compared with those of the control group. Pollmann [24] reported that the fecal Lactobacillus and E. coli counts were not affected when feeding sows with a diet contained Bacillus. The inconsistent results with fecal bacterial populations between the current study and previous reports may be owing to the differences in strains of probiotics, concentrations of

Table 4. Effects of dietary Pediococcus acidilactici ZPA017 supplementation on serum indices of sows at weaning

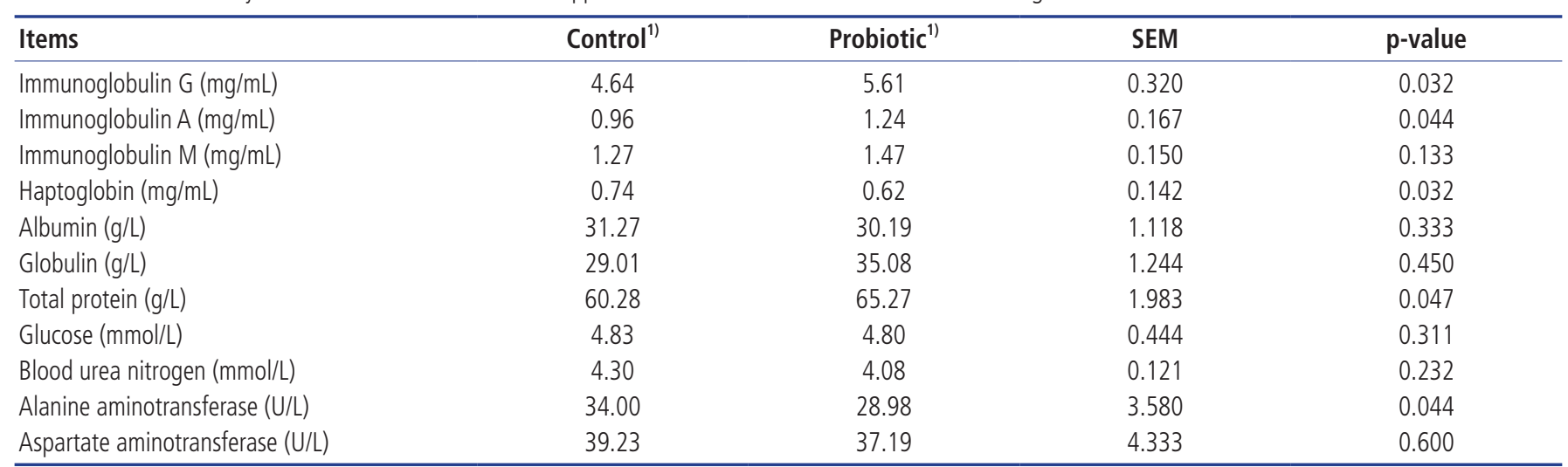

SEM, standard error of means; CFU, colony-forming unit.

${ }^{1)}$ Control, control diet; Probiotic, control diet supplemented with Pediococcus acidilactici ZPA017 $\left(2.40 \times 10^{9} \mathrm{CFU} / \mathrm{kg}\right.$ of diets). 
probiotics in diets, nutrition level and diet sources, housing environment and the age of sows, but further investigations are needed to verify.

Probiotics have the capacity to stimulate the immune system, which is very relevant in pig production to avoid losses related to health reasons (e.g. decreased milk production) of sows and piglets during the peripartal period [25-27]. In pigs, the immunoglobulin concentration is an important immune parameter $[28,29]$. Results of the current study showed that diets supplemented with $P$. acidilactici ZPA017 increased serum IgG and IgA concentrations in sows, demonstrating that $P$. acidilactici ZPA017 had beneficial effect on immune function so as to improve health status and performance of sows. This result agreed with a previous study showing that Lactobacillus johnsonii XS4 supplementation increased the serum IgG concentration in sows [30]. However, the mechanism for enhancing immune function by $P$. acidilactici was not clear, the reason might be that the probiotic could regulate intestinal microflora and stimulate intestinal tissue to produce immunoglobulin [31,32]. In addition, the enhancement of immunoglobulin in serum could be beneficial to piglets because immunoglobulin can be translocated from blood to colostrum [33,34], which provides humoral immune protection for the new-born piglets and possibly protects them against potential diseases [35]. Although the sows' colostrum and milk immunoglobulin levels were not observed in this study, the decreased diarrhea incidence of piglets in sows fed $P$. acidilactici ZPA017 might be related to the improved serum immunoglobulin concentrations in sows.

Sows with dietary P. acidilactici ZPA017 supplementation had lower serum haptoglobin concentration than sows fed control diets. Haptoglobin is one type of acute phase proteins and has been identified as a sensitive indicator of health status of pigs [36]. Its concentration has been found to increase in the serum of pigs suffering from inflammation, stress and infection or tissue injury $[37,38]$. The lower haptoglobin concentration suggested that $P$. acidilactici ZPA017 had a beneficial effect helping sows to sustain a good health status. In terms of serum biochemical indicators, total protein is an indicator of adequacy of quantity and quality of diets as well as efficiency of utilization of the dietary protein by the pig $[39,40]$, the increased total protein concentration in sows with dietary supplementation with $P$. acidilactici ZPA017 suggested that the crude protein digestibility was improved and more protein was available for utilization [41]. Alanine aminotransferase is principally found in the liver and is a descriptor of hepatic disease and liver cytolysis in pigs [42]. The lower level of alanine aminotransferase activity in sows supplemented with P. acidilactici ZPA017 compared with sows fed control diets indicated that $P$. acidilactici ZPA017 supplementation could alleviate the liver damage and improve the normal function of liver [43]. Similar trends were also observed by Wang et al [30], who showed that Lactobacillus johnsonii XS4 supplementation increased serum total protein and decreased alanine aminotransferase levels in sows.

\section{CONCLUSION}

In conclusion, $P$. acidilactici ZPA017 supplementation to sows during late gestation and lactation had positive effects on reproductive performance, intestinal microflora balance and immunity. The present study showed that $P$. acidilactici ZPA017 could be an alternative to antibiotics for use as a feed additive in diets of sows. Further studies are needed to investigate the proper dosage to be administered and the possible mechanism of probiotic actions of $P$. acidilactici ZPA017.

\section{CONFLICT OF INTEREST}

We certify that there is no conflict of interest with any financial organization regarding the material discussed in the manuscript.

\section{ACKNOWLEDGMENTS}

This work was supported financially by Beijing Innovation Consortium of Agriculture Research System (BAIC02-2019), Youth Foundation of Beijing Academy of Agriculture and Forestry Sciences (QNJJ201812), and the Special Program on Science and Technology Innovation Capacity Building of BAAFS (KJCX201914). We would like to thank Beijing Xiqingminfeng Farm (Beijing, China) for their assistance with these studies.

\section{REFERENCES}

1. Maxwell CV, Combs GE, Knabe DA, Kornegay ET, Noland PR. Effect of dietary chlortetracycline during breeding and (or) farrowing and lactation on reproductive performance of sows: a cooperative study. J Anim Sci 1994;72:3169-76. https://doi.org/10.2527/1994.72123169x

2. Kyriakis SC, Vassilopoulos V, Demade I, Kissels W, Polizopoulou Z, Milner CK. The effect of virginiamycin on sow and litter performance. Anim Prod 1992;55:431-6. https://doi. org/10.1017/S0003356100021139

3. Kantas D, Vassilopoulos V, Kyriakis SC, Saoulidis K. A dose titration study on the effect of virginiamycin on gilt/sow and piglet performance. J Vet Med A 1998;45:525-33.

4. Fuller R. Probiotics in man and animals. J Appl Bacteriol 1989;66:365-78.

5. Böhmer BM, Kramer W, Roth-Maier DA. Dietary probiotic supplementation and resulting effects on performance, health status, and microbial characteristics of primiparous sows. J 
Anim Physiol Anim Nutr 2006;90:309-15. https://doi.org/10. 1111/j.1439-0396.2005.00601.x

6. Alexopoulos C, Georgoulakis IE, Tzivara A, Kritas SK, Siochu A, Kyriakis SC. Field evaluation of the efficacy of a probiotic containing Bacillus licheniformis and Bacillus subtilis spores, on the health status and performance of sows and their litters. J Anim Physiol Anim Nutr 2004;88:381-92. https://doi.org/ 10.1111/j.1439-0396.2004.00492.x

7. Castex M, Lemaire P, Wabete N, Chim L. Effect of probiotic Pediococcus acidilactici on antioxidant defences and oxidative stress of Litopenaeus stylirostris under Vibrio nigripulchritudo challenge. Fish Shellfish Immun 2010;28:622-31.

8. Lessard M, Dupuis M, Gagnon N, et al. Administration of Pediococcus acidilactici or Saccharomyces cerevisiae boulardii modulates development of porcine mucosal immunity and reduces intestinal bacterial translocation after Escherichia coli challenge. J Anim Sci 2009;87:922-34. https://doi.org/10.2527/ jas.2008-0919

9. NRC. Nutrient requirements of swine (11th Ed.). Washington, DC, USA: National Academy Press; 2012.

10. Wang YZ, Shan TZ, Xu ZR, Feng J, Wang ZQ. Effects of the lactoferrin (LF) on growth performance, intestinal microflora and morphology of weanling pigs. Anim Feed Sci Technol 2007;135:263-72. https://doi.org/10.1016/j.anifeedsci.2006. 07.013

11. Choi JY, Kim JS, Ingale SL, et al. Effect of potential multimicrobe probiotic product processed by high drying temperature and antibiotic on performance of weanling pigs. J Anim Sci 2011;89:1795-804. https://doi.org/10.2527/jas.2009-2794

12. Giang HH, Viet TQ, Ogle B, Lindberg JE. Growth performance, digestibility, gut environment and health status in weaned piglets fed a diet supplemented with potentially probiotic complexes of lactic acid bacteria. Livest Sci 2010;129:95-103. https://doi.org/10.1016/j.livsci.2010.01.010

13. Upadhaya SD, Kim SC, Valientes RA, Kim IH. The effect of Bacillus-based feed additive on growth performance, nutrient digestibility, fecal gas emission, and pen cleanup characteristics of growing-finishing pigs. Asian-Australas J Anim Sci 2015; 28:999-1005. https://doi.org/10.5713/ajas.15.0066

14. Yirga $H$. The use of probiotics in animal nutrition. J Probiot Health 2015;3:132. https://doi.org/10.4172/2329-8901.1000132

15. Alexopoulos C, Karagiannidis A, Kritas SK, Boscos C, Georgoulakis IE, Kyriakis SC. Field evaluation of a bioregulator containing live Bacillus cereus spores on health status and performance of sows and their litters. J Vet Med A Physiol Pathol Clin Med 2001:48:137-45. https://doi.org/10.1046/ j.1439-0442.2001.00342.x

16. Taras D, Vahjen W, Macha M, Simon O. Response of performance characteristics and fecal consistency to long-lasting dietary supplementation with the probiotic strain Bacillus cereus var. toyoi to sows and piglets. Arch Anim Nutr 2005;59: 405-17. https://doi.org/10.1080/17450390500353168
17. Zanello G, Meurens F, Serreau D, et al. Effects of dietary yeast strains on immunoglobulin in colostrum and milk of sows. Vet Immunol Immunopathol 2013;152:20-7. https://doi.org/ 10.1016/j.vetimm.2012.09.023

18. Kim SW, Brandherm M, Freeland M, Newton B, Cook D, Yoon I. Effects of yeast culture supplementation to gestation and lactation diets on growth of nursing piglets. Asian-Australas J Anim Sci 2008;21:1011-4. https://doi.org/10.5713/ajas.2008. 70438

19. Taras D, Vahjen W, Macha M, Simon O. Performance, diarrhea incidence, and occurrence of Escherichia coli virulence genes during long-term administration of a probiotic Enterococcus faecium strain to sows and piglets. J Anim Sci 2006;84:608-17. https://doi.org/10.2527/2006.843608x

20. Parvez S, Malik KA, Ah Kang S, Kim HY. Probiotics and their fermented food products are beneficial for health. J Appl Microbiol 2006;100:1171-85. https://doi.org/10.1111/j.13652672.2006.02963.x

21. Heyman M, Ménard S. Probiotic microorganisms: how they affect intestinal pathophysiology. Cell Mol Life Sci 2002;59: 1151-65.

22. Brashears MM, Jaroni D, Trimble J. Isolation, selection, and characterization of lactic acid bacteria for a competitive exclusion product to reduce shedding of Escherichia coli O157:H7 in cattle. J Food Prot 2003;66:355-63. https://doi.org/10.4315/ 0362-028X-66.3.355

23. Scharek L, Guth J, Reiter K, et al. Influence of a probiotic Enterococcus faecium strain on development of the immune system of sows and piglets. Vet Immunol Immunopathol 2005;105:151-61. https://doi.org/10.1016/j.vetimm.2004.12. 022

24. Pollmann DS. Probiotics in pig diets. In: Haresign DJA, editor. Recent advances in animal nutrition. London, UK: ButterworthHeinemann; 1986. pp. 193-205.

25. Christensen HR, Frokiaer H, Pestka JJ. Lactobacilli differentially modulate expression of cytokines and maturation surface markers in murine dendritic cells. J Immunol 2002;168:1718. https://doi.org/10.4049/jimmunol.168.1.171

26. Schierack P, Wieler LH, Taras D, et al. Bacillus cereus var. toyoi enhanced systemic immune response in piglets. Vet Immunol Immunopathol 2007;118:1-11. https://doi.org/10.1016/j.vetimm. 2007.03.006

27. Wheeler MB, Bleck GT, Donovan SM. Transgenic alteration of sow milk to improve piglet growth and health. Reprod Suppl 2001;58:313-24.

28. Lauridsen C. Evaluation of the effect of increasing dietary vitamin $\mathrm{E}$ in combination with different fat sources on performance, humoral immune responses and antioxidant status of weaned pigs. Anim Feed Sci Technol 2010;158:85-94. https:// doi.org/10.1016/j.anifeedsci.2010.03.015

29. Lee IK, Kye YC, Kim G, et al. Stress, nutrition, and intestinal immune responses in pigs - a review. Asian-Australas J Anim 
Sci 2016;29:1075-82. https://doi.org/10.5713/ajas.16.0118

30. Wang J, Ji HF, Hou CL, et al. Effects of Lactobacillus johnsonii XS4 supplementation on reproductive performance, gut environment, and blood biochemical and immunological index in lactating sows. Livest Sci 2014;164:96-101. https:// doi.org/10.1016/j.livsci.2014.03.008

31. Sánchez B, Gueimonde M, Peña AS, Bernoda D. Intestinal microbiota as modulators of the immune system. J Immunol Res 2015;2015:Article ID 159094. https://dx.doi.org/10.1155/ 2015/159094

32. Jang YD, Kang KW, Piao LG, et al. Effects of live yeast supplementation to gestation and lactation diets on reproductive performance, immunological parameters and milk composition in sows. Livest Sci 2013;152:167-73. https://doi.org/10. 1016/j.livsci.2012.12.022

33. Bourne FJ, Curtis J. The transfer of immunoglobins IgG, IgA and IgM from serum to colostrum and milk in the sow. Immunology 1973;24:157-62.

34. Salmon H, Berri M, Gerdts V, Meurens F. Humoral and cellular factors of maternal immunity in swine. Dev Comp Immunol 2009;33:384-93. https://doi.org/10.1016/j.dci.2008.07.007

35. Le Dividich J, Rooke JA, Herpin P. Nutritional and immunological importance of colostrum for the new-born pig. J Agric Sci 2005;143:469-85. https://doi.org/10.1017/S002185960 5005642

36. Heegaard PMH, Klausen J, Nielsen JP, et al. The porcine acute phase response to infection with Actinobacillus pleuropneumoniae. Haptoglobin, C-reactive protein, major acute phase protein and serum amyloid A protein are sensitive indicators of infection. Comp Biochem Physiol B Biochem Mol Biol 1998;119:365-73. https://doi.org/10.1016/S0305-0491(97)00 362-3

37. Eckersall PD. Acute phase proteins as markers of infection and inflammation: monitoring animal health, animal welfare and food safety. Irish Vet J 2000;53:307-11.

38. Petersen HH, Nielsen JP, Heegaard PHM. Application of acute phase protein measurements in veterinary clinical chemistry. Vet Res 2004;35:163-87. https://doi.org/10.1051/vetres:2004002

39. Štukelj M, Valencak Z, Krsnik M, Svete AN. The effect of the combination of acids and tannin in diet on the performance and selected biochemical, haematological and antioxidant enzyme parameters in grower pigs. Acta Vet Scand 2010;52: 19. https://doi.org/10.1186/1751-0147-52-19

40. Lowrey RS, Pond WG, Barnes RH, Krook L, Loosli JK. Influence of caloric level and protein quality on the manifestations of protein deficiency in the young pig. J Nutr 1962;78:24552. https://doi.org/10.1093/jn/78.2.245

41. Bajagai YS, Klieve AV, Dart PJ, Bryden WL. Probiotics in animal nutrition - production, impact and regulation. In: Makkar HPS, editor. FAO animal production and health paper No. 179. Rome, Italy: Food and Agriculture Organization of the United Nation; 2016.

42. Johnston DE. Special considerations in interpreting liver function tests. Am Fam Physician 1999;59:2223-30.

43. Hlatini VA, Chimonyo M. Nutritionally-related blood metabolites and liver enzymes in growing pigs fed on Acacia tortilis treated with polyethylene glycol. Livest Sci 2016;187:158-61. https://doi.org/10.1016/j.livsci.2016.03.011 